This item was submitted to Loughborough's Research Repository by the author.

Items in Figshare are protected by copyright, with all rights reserved, unless otherwise indicated.

\title{
Re-examining value co-creation in the age of interactive service robots
}

PLEASE CITE THE PUBLISHED VERSION

PUBLISHER

(c) Academy of Marketing Science

VERSION

AM (Accepted Manuscript)

\section{PUBLISHER STATEMENT}

This work is made available according to the conditions of the Creative Commons Attribution-NonCommercialNoDerivatives 4.0 International (CC BY-NC-ND 4.0) licence. Full details of this licence are available at: https://creativecommons.org/licenses/by-nc-nd/4.0/

\section{LICENCE}

CC BY-NC-ND 4.0

\section{REPOSITORY RECORD}

Barnett, Willy, Adrienne Foos, Thorsten Gruber, Debbie I. Keeling, Kathy Keeling, and Linda Nasr. 2019. "Reexamining Value Co-creation in the Age of Interactive Service Robots". figshare.

https://hdl.handle.net/2134/17125. 


\section{Re-Examining Value Co-Creation in the Age of Interactive Service Robots* W Barnett, A Foos, T Gruber, DI Keeling, K Keeling, L Nasr}

\section{Willy Barnett}

PhD Candidate in Marketing \& Service Management, Manchester Business School, University of Manchester, Booth Street West, Manchester M15 6PB, UK

E-mail: willy.barnett@postgrad.mbs.ac.uk

Tel: +44-(0)744-791-4847

\section{Adrienne Foos}

PhD Candidate, Manchester Business School, University of Manchester, Booth Street West, Manchester, M15 6PB, UK.

E-mail: adrienne.foos@postgrad.mbs.ac.uk

\section{Thorsten Gruber}

Chair in Marketing and Service Management, Loughborough University, Ashby Road, Loughborough LE11 3TU, UK

E-mail: t.gruber@lboro.ac.uk

Tel: +44 (0) 1509228274

\section{Debbie Isobel Keeling (corresponding author)}

Associate Professor in Marketing, School of Business and Economics, Loughborough University, Ashby Road, LE11 3TU

E-mail: D.I.Keeling@lboro.ac.uk

Tel: +44 (0)1509 223117

\section{Kathleen Keeling}

Associate Professor in Research Methods and Statistics, Manchester Business School, The University of Manchester, Booth Street West, Manchester, M15 6PB, UK

E-mail: kathy.keeling@manchester.ac.uk 


\section{Linda Nasr}

Assistant Professor in Marketing, Manchester Business School, University of Manchester, Booth Street West, Manchester, M15 6PB, UK.

E-mail: linda.nasr@mbs.ac.uk

Tel: +44 (0) 1613063464

*All authors contributed equally 


\section{Re-Examining Value Co-Creation in the Age of Interactive Service Robots}

With robots increasingly considered as viable service agents, marketers must explore the nature of value co-creation during service interactions and the consequences for the wider nature of relationships between service providers and customers. This study investigates the nature of the direct interaction between humans and robots and the implications for value cocreation. The aim is to reveal the underlying structures that influence user opinions of robot roles and value-in-use, and so inform the debate on social implications of robot service. Such insights will create awareness for the changing nature of service encounters and help marketers promote positive interactions.

Recently, Edvardsson et al. (2011) expanded our understanding of service dominant logic by pointing out that value co-creation follows social structures and occurs within social systems in which both customers and employees adopt certain roles during their interaction. Interaction means that two or more actors are in contact with and influence each other. In the context of this research, interaction involves service encounters between customers and interactive service robots (ISRs). The role of companies and organizations is to help customers in their value creation by providing them with necessary resources and processes (e.g. information, goods, and service activities). Value creation, a process facilitated by companies and organizations, is regarded as a process after which customers should be (or at least feel) better off than before (Grönroos 2008; 2011). According to Grönroos (2011), value co-creation can solely occur when frontline employees and customers are interacting directly (as opposed to organizations being limited to only making value propositions, as posited by Vargo and Lusch in 2004). Different outcomes are possible depending on how the interaction progresses (Grönroos 2012), therefore, frontline employees interacting with customers play an important role as they influence their customers' value creation process either positively (value creation) or negatively (value destruction) (Grönroos 2011; Echeverri and Skalen 2011).

Research on the interaction and service encounters started mostly in the 1970s. More recently, interest shifted away from investigating face-to-face service encounters and moved more towards other service relationships. Due to the rapid advancement of robotic technology, we may soon witness a 'comeback' of traditional service encounter research, this time, however, focusing on interactions between customers and ISRs. Thus, technological changes in the macro-environment indeed have a significant impact on how the roles of both customers and employees change in service environments. Already deployed in defense, manufacturing, and warehousing, the integration of robots into service environments is closer than ever (AlonsoMartin and Salichs 2011). A new generation of social robots (i.e. ISRs) capable of working within service environments and interacting with customers through various service encounters (such as healthcare and education) is evolving. Although these technological developments may quell some emerging societal problems, such as a shortage of care workers for an increasingly elderly population, the interactive nature of the service encounter also brings with it new challenges. Bartneck and Forlizzi (2004) define a social robot as "an autonomous or semi-autonomous robot that interacts and communicates with humans by following the behavioral norms expected by the people with whom the robot is intended to interact" (p. 593). This definition 
clearly assumes that humans are assigning roles to the robot in the interaction. However, the nature of those roles and the consequences for service outcomes, perceived value, and relationships with providers of customer-robot service interactions can potentially be destructive. For example, Torrey et al. (2008) find possible negative social and psychological effects for users stemming for accepting help from service assistive robots. They link negative outcomes to the nature and content of the interaction, providing the counter-intuitive recommendation that ISRs might mitigate negative social outcomes resulting from accepting help through emphasizing their 'machine like' qualities.

These studies speak to wider consequences, as they strongly suggest that other social changes around the nature of relationships between service providers and service customers could arise from misunderstandings of value sought and user perceptions of robots' place in society. If ISRs are to play a positive role in delivering service, marketers need to understand the interplay between roles assigned to ISRs and value co-creation. Applying the work of Grönroos (2011) and Edvardsson et al. (2011) to this new situation would suggest that successful integration of such social robots into service environments presumes effective interaction between robots and customers; which in turn is impacted by customers' perceptions of the role status of robots. Robotics research has focused particularly on developing socially interactive robots, e.g., realistic movements, personalities, emotions, social interaction, and communication (e.g. Fong et al. 2003, Mori 1970), with an assumption that this technology will deliver value in the service exchange. Our study questions this assumption, arguing that to offer a viable route for service delivery we must comprehensively understand customers' feelings about robots in specific service contexts: healthcare, education and retailing.

\section{Research Method}

Our study utilizes the Zaltman Metaphor Elicitation Technique (ZMET). ZMET integrates the visual projection technique, in-depth personal laddering interview, and qualitative dataprocessing techniques (Lee et al. 2003). According to the method, a purposive sample collects images around a subject chosen by the researcher. We conducted three ZMET studies, one for each service context, asking up to twenty respondents (Reynolds et al. 2001) respectively for each study to bring images related to what interacting with a robot in that service context means to them in either retailing, healthcare, or education. Some information was provided about each type of use so all participants had a minimum shared knowledge. One-to-one guided conversations followed, initially on what the service interaction means to them at present in the context, then, around a repertory grid framework (Kelly 1955; 1963) for the relative meaning of the images; followed by a short laddering interview. Narrative analysis of the stories in the first part of the interview builds conceptualization of the main thematic categories. The laddering interview show how attributes of the robot and interaction are ultimately linked to the values or beliefs that are strengthened or satisfied by the consequences of use (Reynolds and Gutman 1988). The complete ZMET technique allows for the discovery of positive and negative connotations that users associate with interactions with ISRs and draws out the underlying structures that influence user opinions of robot roles and value-in-use. 


\section{Findings}

Laddering: The researchers coded the sequences of A-C-Vs (ladders) using Schwartz's Universal Values for end value categories (Schwartz 2004). A total of 267 ladders were entered into the decision-support software LADDERMAP ${ }^{\circledR}$ to produce a Hierarchical Value Map (HVM), displaying the links between Attributes, Consequences and underpinning Values.

The two most important values were "self-direction $(n=19)$ " and "security $(n=18)$ ". These two values were not only the most mentioned, but also possessed the majority of the strongest consequences links. "Self-direction" represented participants' need for independence. For example, in a retail setting many participants felt that service robots would positively impact their ability to make decisions and make better use of their time. Several respondents mentioned that the less time they spent in a retail store, the more time they would have to deal with more important affairs. In order for participants to perceive self-direction, it was important for robots to not violate machine-like expectations, such as returning the correct amount of change at check out. "Security" represented feelings of trust and sincerity. The majority of participants felt that robots were unbiased and non-judgmental, and therefore felt the robot would not try to upsell them or segment them into stereotypical shopping categories. Paradoxically, although robots were perceived as trustworthy in a retail setting, many participants felt that robots were incapable of being sincere. For example, one participant noted that if a robot asks how his day was, he would be immediately put off because he would know that the robot really did not care.

The attribute-to-consequence link of "personality $(n=15)$ "-to-"human interaction $(n=18)$ " displayed the strongest connections to "security" and "self-direction". Participants related a robot's personality to that of a service employee. Humanlike service behaviors such as friendliness and empathy were examples of perceptions of personality. The consequence of "human interaction" was viewed as the extent in which a participant would want to interact with the robot. This consequence was also viewed in a paradoxical nature. For example, most participants felt that the personality of the robot would directly determine whether or not there would be interaction, however, some participants felt that a robot with a limited personality (i.e. less talkative, less personable) would actually be preferable to a human service employee due to the robot's inability to have bad moods. In contrast, other participants mentioned that they would be more willing to interact with a robot that displayed social norms such as politeness embedded into their personality. It is interesting to note that these same participants expressed reluctance in reciprocating the same norms.

The consequence of "service experience $(n=15)$ " additionally had strong linkages to the values of "security" and "self-direction". "Service experience" was also the direct consequence of "faster service $(n=19)$ " (described as the robot's ability to expedite service transactions) and "service failure $(n=19)$ " (described as robot malfunctions). The majority of participants agreed that a speedy, error free robot interaction would result in a positive experience. A paradoxical characteristic also existed with the consequence of "service experience". We found that many participants felt that while service experience is enhanced by functional attributes such as 
"precision" and "speed", it is also degraded by personality characteristics such as empathy and remorse - contradicting the typical expectations of a human-to-human retail interaction.

Visual Metaphors: Several central metaphorical themes emerged to enhance our understanding of perceived value from robot interaction.

Metaphor: "We've barely scratched the surface." The metaphor of an iceberg relates not only to the idea of an icy coldness but also that the visible area of an iceberg that is seen above water is a fraction of the entire iceberg. Many participants perceived robots to be void of personality or a soul. The terms "cold" and "empty" often described the perceived interaction with a robot in a retail scenario. The ability to feel a "connection" during a service interaction was viewed as highly important to most participants. Therefore, the robot's perceived lack of personable traits would negatively impact participants' service experience.

Metaphor: "You make me want to pull my hair out." The metaphor relates to the idea that some people may become so frustrated that they would pull their hair as a means of releasing stress. With regards to robots in a retail setting, majority of the participants felt that interactions with a robot might lead to frustration. The reasons mentioned were inability to understand human speech and service failures, such as making mistakes at check out. Participants felt that there would be a trade-off for level of frustration and time saved e.g. they were willing to deal with frustration if the robot presented a faster option for service.

Metaphor: "Our lives will resemble the Planet of the Apes." The metaphor relates to the 2011 movie, Rise of the Planet of the Apes, and represents the transition from a world of human control to one of primate control. In this view, many participants felt that introduction of robots in a retail setting would render human shoppers as simple components of a larger system. The participants felt that robots would remove the social characteristic from a service experience and humans would act in a standard mechanized manner, with little individuality.

Metaphor: "The life struggle begins." The metaphor relates to the perception of internal and external conflicts that individuals face when they have no means of supporting themselves financially. A large number of participants expressed concern for service workers who may lose their jobs due to the implementation of service robots. In this view, participants' felt that sustainability of the service industries, the economy, and ultimately society, would be threatened if viable robot employees were implemented.

Service Tasks: Several participants mentioned tasks they could envision a robot conducting in a service setting. For example, we compiled a list of the most mentioned retail tasks, agreeing as a group on 3 main categories: physical assistance, emotional support, and information source. Physical assistance consisted of utilizing the robot to perform tasks on behalf of a customer. In most cases, the customer did not have to be physically present. Examples include, carrying heavy items to the car, retrieving items from high shelving, and collecting items while the customer spent time with friends and family. Emotional support consisted of the robot performing tasks in co-operation with the customer. These tasks could be classified as a 
partnership, where the robot alleviates some of the emotional burden from the customer. Examples included reducing stress by allowing the robot to retrieve shopping items, assisting the customer with planning meals, and allowing the customer to focus on shopping while the robot entertains their child. The final category, information source, consisted of robots providing factual information to the customer. In these examples, the robot would explain the technical features of products, advertise and promote products, and perform complex calculations such as determining the optimal products to fit within a budget.

\section{Conclusion}

Taken together, the results of the laddering and metaphor analysis highlight the conflicting meanings consumers derive from robot interaction, and the various service tasks that these meanings can be applied to. The most frequent conflict is between the values of self-direction and security. With self-direction, participants expressed the desire to assert their independence and individualism. Participants wanted to be in control of their choices and be treated as individuals. With security, participants worried that interacting with robots would make them lose a sense of belonging and would make them feel lonely. The tension between these values is related to the overarching conflict between openness to change and conservation. The implications of this paradox are that participants expected a robot to behave both machine-like in terms of speed and precision, while also maintaining human attributes, such as empathy (without other human attributes, such as mood swings, mistakes, and biases). Participants expected robots to conform to social norms towards them, while not reciprocating politeness themselves. In interacting with consumers, robots are expected to be super-human.

Another conflict arises between the overarching values of self-enhancement (including power and achievement) and self-transcendence (including benevolence and universalism). Participants desired to be treated with respect and importance during interactions with robots. However, they were also skeptical of the sincerity of the interaction and suspicious of the motives of robots. Participants revealed that interacting with robots represented progress, improvement, and modernity, while also feeling concerned about a future with robots. They feared the potential loss of jobs and the natural environment. These tensions highlight the moral hazard of robot interaction. The underlying concern is whether the robot is working as an agent on behalf of the organization rather than the customer. In being programed to rigidly follow the organization's best interest, the interaction itself loses meaning and authenticity for the customer. This is linked to the concern for the quality of mercy, or the humanness of the tasks themselves. If the interaction is devoid of humanity, the fear of human replacement and concern for social welfare is emphasized.

The conflicts participants expressed reveal both the depth and breadth of meanings people associate with interacting with robots. The feelings conveyed ranged from how participants feel about themselves, how they wish to behave and be perceived, and how they want robots to behave, to their concerns about the impact of robots on the progression of society as a whole.

References are available on request 